\title{
IMPLIKATUR WACANA HUMOR GELAR WICARA INI TALKSHOW DI NET TV
}

\author{
Nur Ifansyah \& Sumarlam \\ Universitas Sebelas Maret \\ ifan.syahnuur@gmail.com, sumarlamwd@gmail.com
}

Naskah diterima: 10 Januari 2017.; direvisi: 21 April 2017; disetujui: 22 April 2017

\begin{abstract}
The goal reached in this study is to describe and explain (1) implicature entity; (2) violation of cooperative principle; and (3) violation of politeness principle. The research is qualitative approach in content analysis and pragmatics theory designed. Data is humor discourse on Ini Talkshow program at NET TV, collected by recoding and taking a note. Data validation investigated by applying data triangulation. Then, data analyzed by using interactive models. The result study presented that (1) humor discourse of impicature entity on Ini Talkshow such as mentioning, expressing, refusing, instituating, judging, accusing, claiming, asking/want, mocking, evicting, and threatening; (2) violated of cooperative principle maxim such as quantity, quality, relevance, and manner; and (3) besides violating cooperative principle, the implicature expressing also violated positive and negative politeness. This violation was done deliberately in case to create the humor sense of audience minds.
\end{abstract}

Keywords: Implicature, Humor Discourse, Ini Talkshow Program

\begin{abstract}
ABSTRAK
Tujuan yang ingin dicapai penelitian ini adalah untuk mendeskripsikan dan menjelaskan (1) wujud implikatur; (2) pelanggaran terhadap prinsip kerja sama; dan (3) pelanggaran terhadap prinsip kesantunan. Penelitian ini menggunakan pendekatan kualitatif dengan metode analisis isi dan ancangan teori pragmatik. Data berupa wacana humor pada gelar wicara Ini Talkshow yang ditayangkan NET TV, yang dikumpulkan dengan teknik rekam dan catat. Keabsahan data diperiksa dengan triangulasi data. Data kemudian dianalisis dengan model interaktif. Hasil penelitian menunjukkan bahwa (1) wujud implikatur wacana humor gelar wicara Ini Talkshow berupa menyebutkan, menyatakan, menolak, menyindir, memprotes, menuduh, mengklaim, meminta/memohon, mengejek, mengusir, dan mengancam; (2) maksim prinsip kerja sama yang dilanggar meliputi maksim kualitas, maksim, hubungan, dan maksim cara; dan (3) di samping melanggar prinsip kerja sama, pengutaraan implikatur juga melanggar kesantunan positif dan kesantunan negatif. Pelanggaran itu dilakukan secara sengaja semata-mata untuk menciptakan suasana humor di benak penonton.
\end{abstract}

Kata kunci: Implikatur, Wacana Humor, Gelar Wicara Ini Talkshow 


\section{PENDAHULUAN}

Sepanjang hidupnya, manusia tidak pernah lepas dari upaya menyampaikan makna kepada sesamanya melalui wahana bahasa yang dipahami dan dikuasai bersama. Aktivitas menyampaikan makna merupakan manifestasi hakikatnya sebagai makhluk sosial yang senantiasa berkomunikasi (berbahasa) untuk mencapai suatu tujuan. Makna adalah komponen utama bahasa dan, dengan begitu, ketika makna disampaikan, itu berarti bahasa sedang menjalankan fungsinya. Bahasa memiliki dua fungsi utama, yakni transaksional dan interaksional (Brown dan Yule, 1983: 1). Sejajar dengan fungsi itu, Holmes (2013: 275) menyebutnya sebagai fungsi referensial dan fungsi afektif. Yang pertama itu merujuk ke fungsi dengan tujuan menyampaikan informasi (pesan); sedangkan, yang kedua merupakan fungsi yang bertujuan memantapkan dan memelihara hubungan sosial.

Interaksi sosial selalu menuntut manusia untuk berkomunikasi dengan memerhatikan fitur konteks terkait. Kegagalan komunikasi, atau bahkan kekacauan, akan terjadi bilamana hal itu tidak diindahkan. Tuntutan imperatif itu menjadi penting salah satunya karena kebiasaan manusia dalam menyampaikan makna, yakni secara tidak langsung. Hal demikian menjadi bagian dari bahasan pragmatik sebagai studi penggunaan bahasa dalam konteks (Birner, 2013: 2), spesifiknya pada implikatur percakapan.

Implikatur percakapan merupakan sesuatu yang terimplikasi di dalam percakapan atau yang sengaja dibiarkan implisit dalam penggunaan bahasa (Mey, 2004: 45). Dengan perkataan lain, Implikatur merupakan makna yang tidak disampaikan secara langsung, tetapi diimplisitkan di dalam tuturan. Makna implisit itu lebih banyak daripada makna literal tuturan, sebagaimana ditengarai Yule (2014: 126) bahwa lebih banyak yang dikomunikasikan daripada yang

dikatakan. Horn (2006: 3) menyebut implikatur sebagai komponen makna penu- tur yang merupakan apa yang dimaksud dalam tuturan penutur tanpa menjadi bagian dari apa yang dikatakan. Ini berarti bahwa antara tuturan dan makna implisit tidak memiliki hubungan langsung atau mutlak. Makna itu dapat dipahami melalui konteks yang mewadahi percakapan. Konteks dapat memberikan petunjuk kepada interlokutor (petutur) untuk sampai pada maksud penutur.

Implikatur percakapan lahir dalam suatu percakapan (melalui tindak tutur) dan dilatarbelakangi oleh pelanggaran terhadap prinsip percakapan. Tindak tutur yang jumlahnya sangat banyak, oleh Searle (1969), dikategorikan menjadi lima jenis: representatif, direktif, ekspresif, komisif, dan deklarasi. Dalam pada itu, prinsip percakapan yang dilanggar sehingga melahirkan implikatur ialah prinsip kerja sama (Grice, 1975: 68) dan prinsip kesantunan (Brown dan Levinson, 1987: 70).

Salah satu bentuk wacana pragmatik ialah wacana humor. Humor, menurut Raskin (1985: 1), ditandai oleh adanya stimulus audio atau visual yang bersifat lucu sehingga membuat orang yang mendengar atau melihatnya menjadi tertawa. Hal itu merupakan sifat universal manusia. Raskin (1985: 3-5) juga menyebutkan bahwa terdapat enam faktor penunjang tindak humor (humor act), meliputi partisipan (pembicara dan pendengar), stimulus, pengalaman, psikologi, situasi, dan sosial budaya.

Humor dapat dikatakan sebagai kasus permainan bahasa atau tindakan penggunaan bahasa secara kreatif (Bell dan Pomerantz, 2016: 22). Manusia sebagai homo ludens gemar bermain, termasuk memainkan bahasa secara kreatif dalam pelbagai situasi. Humor yang terjadi dalam interaksi sosial sehari-hari dapat dibagi menjadi tiga kategori (Martin, 2007: 11): (1) lelucon, anekdot yang dikemas dengan lucu yang dihafal dan disebarkan ke orang lain; (2) humor-percakapan spontan, yang diciptakan dengan sengaja oleh individu selama interaksi sosial, dapat berupa verbal 
atau nonverbal; dan (3) humor aksidental atau tanpa disengaja.

Wacana humor menjadi penting untuk diteliti karena hampir semua orang menghadapi situasi lucu, cerita lucu, bahkan pikiran lucu dalam kehidupan sehari-hari. Lebih-lebih, humor memiliki fungsi yang sangat banyak yang, oleh Martin (2007: 15; Bell dan Pomerantz, 2016: 28), dikelompokkan ke dalam tiga kategori, yakni manfaat kognitif dan sosial dari emosi positif kegembiraan, menggunakan humor untuk komunikasi dan pengaruh sosial, dan meringankan dan mengatasi ketegangan atau stres.

Signifikansi humor bagi kehidupan manusia tidak luput dari perhatian media televisi. Hal itu terbukti dengan maraknya acara-acara yang bernuansa humor. Salah satu acara humor yang menarik ialah Ini Talkshow (selanjutnya disingkat IT), yang disiarkan oleh stasiun televisi NET TV. IT merupakan tayangan gelar wicara yang cukup luwes karena menghadirkan bintang-bintang tamu dari pelbagai kalangan, misalnya aktor/aktris, musikus, politikus, tokoh masyarakat, dan sebagainya. Acara ini menyajikan humor dengan teknik yang kekinian (modern) dan menyasar semua segmen pemirsa. Pemandu acara ini dikenal sebagai komedian yang kerap kali menciptakan humor yang segar dan spontan.

Humor mengandung banyak implikatur, meskipun penutur humor itu mungkin tidak menyadarinya. Berdasarkan perspektif pragmatik, implikatur-yang muncul akibat pelanggaran terhadap prinsip percakapan-merupakan potensi besar bagi penciptaan humor. Dengan demikian, perlu dikaji lebih jauh mengenai implikatur yang terkandung di balik penciptaan humor pada acara tersebut. Penelitian ini bertujuan untuk mendeskripsikan dan menjelaskan wujud implikatur dan pelanggaran terhadap prinsip kerja sama dan prinsip kesantunan dalam wacana humor gelar wicara IT.

\section{METODE PENELITIAN}

Penelitian ini merupakan penelitian kualitatif dengan metode analisis isi (content analysis) dan ancangan teori pragmatik. Objek yang diteliti ialah wacana humor gelar wicara IT yang ditayangkan oleh stasiun televisi NET TV. Penayangannya berlangsung selama lima kali dalam seminggu, yakni Senin sampai Jumat, dengan durasi pertayangan sembilan puluh menit-termasuk iklan. Data dikumpulkan selama bulan September 2016 dengan teknik rekam dan catat. Untuk memeriksa keabsahan data, digunakan triangulasi data: data yang didapatkan dari satu episode dirujuk silang dengan data dari episode lainnya. Data itu kemudian dianalisis dengan model interaktif (Miles dan Huberman, 1994: 12).

\section{HASIL PENELITIAN DAN PEM- BAHASAN}

Bagian ini mencakupi tiga hal: (1) wujud implikatur wacana humor gelar wicara IT; (2) pelanggaran terhadap prinsip kerja sama; dan (3) pelanggaran terhadap prinsip kesantunan. Wujud implikatur merupakan maksud yang tidak diutarakan secara literal melalui tuturan penutur, tetapi implisit di dalamnya. Dalam konteks wacana humor gelar wicara IT, ia diciptakan secara sengaja melalui pelanggaran terhadap prinsip kerja sama dan/atau prinsip kesantunan untuk memberikan efek humor kepada para penonton/pendengar.

\section{Wujud Implikatur Wacana Humor Gelar Wicara IT}

Dalam interaksi komunikatif yang terjadi pada gelar wicara IT, pelibat (baik tuan rumah maupun bintang tamu) kerap kali menggunakan implikatur untuk mengutarakan pesan atau keinginannya. Di antara implikatur yang tercipta, terdapat sejumlah implikatur yang dimotivasi oleh upaya menciptakan suasana humor sehingga memberikan efek lucu di benak penonton. Berikut nukilan-nukilan data yang menerangkan wujud implikatur yang dimaksud. 
Konteks: Budi Dalton menjelaskan tentang koleksi kujang-nya [senjata tradisional Sunda].)

Budi:

"Saya ini sedang
menghilangkan paradigma
orang-orang mengenai kle-
niklah gitu, ya. Makanya
suka ada yang ke rumah juga,
"Kang Budi ini kujang-
kujangnya bisa berdiri?"
Kadang-kadang skot jump,
saya bilang.
"Nggak hanya berdiri, skot
jump juga bisa." (IT-
05/WI/28/09)

Konteks: Sule bertanya kepada Meriam Bellina mengenai harapannya terhadap teleserial Catatan Si Boy. Para pemeran Catatan Si Boy kemudian mengamini. Nunung pun ikut mengamini.)

Sule: "Nah, Tante Mer. Dengan adanya teleserial Catatan $\mathrm{Si}$ Boy, apa harapannya?"

Meriam: "Harapannya sama segelegar jaman dulu juga, ya."

Nunung: "Amin."

Meriam: "Kenapa sih ganjalan buku ngomong mulu?" (IT03/WI/26/09)

Penutur (Meriam) pada kutipan di atas sesungguhnya tidak bermaksud untuk meminta jawaban. Dengan modus bertanya dia ingin bertutur secara representatif, yakni menyebut mitra tutur (Nunung) sebagai ganjalan buku. Implikatur menyebutkan itu lahir akibat pelanggaran terhadap kesantunan positif. Sebutan demikian merupakan ancaman bagi keinginan mitra tutur agar apa yang dimilikinya dihargai penutur.

Implikatur berkategori representatif juga terlihat pada wacana berikut. Penutur (Budi) memberikan kontribusi yang tidak didukung oleh bukti yang memadai. Perilaku yang dimaksud, kujang-kujangnya kadang-kadang skot jump, tidak berterima secara rasional. Personifikasi kujang ditujukan sebagai daya evokasi humor bagi penonton, yang ditunjang oleh sikap serius penutur. Tindak tutur memberitahukan pada wacana ini menyiratkan maksud me- nyatakan sesuatu yang tidak didukung bukti dan, dengan demikian, melanggar maksim kualitas.

Pada percakapan di bawah ini, terdapat tindak tutur yang tidak linier dengan fungsi yang diemban. Penutur (Komeng) menimpali permintaan mitranya dengan modus memberitahukan, tetapi mengandung implikasi pragmatis menolak. Efek humor dimunculkan oleh ketidakbergayutan kontribusi penutur terhadap topik percakapan, yakni bertanya karena tersasar dan bertanya kepada bintang tamu. Galibnya ketaklangsungan suatu penolakan dalam percakapan dilakukan atas pertimbangan sosiokultural. Makin lejas fungsi menolak diutarakan, makin tidak santun pula tindak tuturnya, yang mengakibatkan terganggunya hubungan sosial. Akan tetapi, di dalam wacana humor, tindakan itu semata-mata demi kelucuan.

(Konteks: Segmen empat dimulai. Sule meminta Komeng (consultant host) bertanya kepada bintang tamu, Indro Warkop.)

Sule: "Nanya dong!"

Komeng: "Ape?"

Sule: "Nanya sama Om Indro. Ape kek."

Komeng: "Gue nggak nyasar. Ngapain nanya?" (IT-01/WI/23/09)

Data berikut mengandung implikatur menyindir dengan modus mengungkapkan. Implikatur muncul dari pelanggaran terhadap prinsip kerja sama dan prinsip kesantunan. Apa yang dimaksudkan penutur (Komeng) sebetulnya berbeda dengan kenyataannya. Mitra tutur (Andre dan Ikang) memang sama-sama pernah mencalonkan diri sebagai pejabat negara, tetapi keduanya gagal. Pelanggaran terhadap maksim kualitas ini justru menjadi bahan penertawaan penonton karena mereka mengetahui distorsi itu. Kesantunan positif dilanggar sebab sindiran merupakan tindakan yang tidak menghargai keadaan (nasib) mitra tutur. 
(Konteks: Ikang Fawzi dan Andre saling mengungkapkan kesamaan satu sama lain. Komeng tiba-tiba mengungkapkan kesamaan lain mereka.)
Ikang:
"Banyak kesamaan.
Andre: "Kita banyak kesamaan."
Ikang: "Tempat tinggal deketan."
"Alis nggak punya." "Rejeki mudah-mudahan."
Andre:
"Ah, sama dong! Alhamdulillah."
Komeng: "Sama-sama pernah mewakili rakyat."
Ikang: "Yahhh, gagal!" (IT- 07/WI/30/09)

Implikatur berkategori ekspresif juga terdapat pada data percakapan berikutnya. Tuturan penutur (Komeng) bermodus bertanya, tetapi mengemban fungsi pragmatis memprotes. Tindakan ini sebagai bentuk evaluasi terhadap apa yang diutarakan mitra tutur (Andre) yang sekaligus mengakibatkan muka positif mitra tutur terancam. Protes yang diimplisitkan justru mampu menggugah tawa penonton karena kontribusi itu mengandung unsur gurauan, yang berbeda jauh dengan apa yang diprotes.

(Konteks: Saat Mulan Jameela menjelaskan ihwal anak-anaknya, Andre bertanya mengenai masa depan anaknya, apakah akan diarahkan ke dunia hiburan, sebagaimana kedua orang tuanya.)

$\begin{array}{ll}\text { Andre: } & \text { "Untuk kegiatan di dunia } \\ & \begin{array}{l}\text { hiburan, gimana?" "Emang } \\ \text { nantinya mau diarahkan ke } \\ \text { dunia hiburan juga anak- } \\ \text { anak?" } \\ \text { Sule: }\end{array} \\ \text { Komeng: } & \begin{array}{l}\text { orang tua, mau pipis arahin." } \\ \text { Masa dia pipis di kulkas, } \\ \text { ye? Ah, pertanyaannya. } \\ \text { (IT-04/WI/28/09) }\end{array}\end{array}$

Jika tindak tutur bertanya pada data di atas berimplikasi pragmatis memprotes, pada data berikut memunculkan implikasi pragmatis menuduh. Implikasi ini muncul akibat pelanggaran terhadap kesantunan positif. Tuduhan yang dialamatkan kepada mitra tutur (Adul) mengancam muka positif karena usaha mitra tutur sebagai satpam dalam melindungi Westny tidak dihargai, justru ditimpali tuduhan. Sebaliknya, penonton sontak tertawa riuh karena tuduhan itu dirasakan mengandung nilai rasa humor.

(Konteks: Adul [sekuriti/satpam] dalam keadaan babak belur datang bersama Westny. Sule dan Komeng penasaran dengan kondisi Adul.)

Sule: "Kasihan banget. Kenapa ini?"

Westny: "Aku digodain tadi sama cowok."

Sule: "Kamu digodain sama cowok? Terus?"

Westny: "Terus akhirnya diancam,

Komeng: "Sini (memanggil Adul)!" "Kamu nyolong motor, ya?"

Sule: Mana ada sekuriti nyolong motor." (IT-02/WI/26/09)

Salah seorang penutur (Budi) pada nukilan data terakhir di atas bertutur representatif memberitahukan. Namun, kontribusi yang disumbangkan sebetulnya bukanlah ditujukan untuk memberikan informasi kepada mitra tutur, melainkan mengklaim sesuatu yang dimaksudkan dalam tuturannya. Kontribusi itu tampak jelas melanggar maksim hubungan karena tidak relevan dengan informasi yang dibutuhkan oleh mitra tutur. Ketidakberhubungan itu justru disambut gelak penonton sebab timpalan beli dodol di Garut terasa menggelikan untuk pertanyaan tentang ada keluarga di Garut.

(Konteks: Sule bertanya sekaligus mengonfirmasi kepada para bintang tamu mengenai keluarga mereka di Garut bersangkutan dengan musibah banjir di sana.)

Sule: "Kemarin-kemarin, Kang Budi, katanya ada keluarga di Garut?"

Budi: "Dekat sih."

Sule: "Teh Mulan juga ada, ya?"

Mulan: "Kalau saya emang orang Garut, Malangbong."

Hetty: "Kalau Mamah di Leles."

Budi: "Kalau saya, ibu saya dari Cia- 
mis, bapak saya Sumedang, tapi suka beli dodol di Garut." (IT-06/WI/28/09)

\section{Pelanggaran terhadap Prinsip Kerja Sama}

Salah satu kelemahan prinsip kerja sama ialah tidak dapat menjelaskan mengapa manusia sering menggunakan cara yang tidak langsung untuk menyampaikan apa yang mereka maksud (Leech, 1983: 80), sehingga prinsip ini tampak sering dilanggar dalam komunikasi yang wajar. Ketidaklangsungan itu terutama dimotivasi oleh keinginan untuk bertindak santun kepada orang lain. Namun, interaksi verbal dalam wacana humor memiliki realitas yang berbeda. Pelanggaran terhadap prinsip kerja sama ditujukan untuk menunjang kelucuan, alihalih menunjukkan kesantunan.

Efek humor salah satunya dapat dicapai dengan melucutkan kebenaran dalam bertutur. Artinya, tuturan yang disumbangkan dalam suatu interaksi komunikatif tidak didukung oleh buktibukti yang adekuat. Wacana berikut menunjukkan hal itu.

(Konteks: Sule berperan sebagai Michael Jackson. Ia berdansa moonwalk di depan Andre dan Komeng.)

Andre: "Ini dalam rangka apa, MJ?"

Sule: "Dalam rangka hari pacul sedunia."

Andre: "Jadi, mengadakan tour, ya?" (IT-03/PKS/29/09)

Data tersebut menunjukkan pelanggaran terhadap prinsip kerja sama. Jawaban yang diberikan Sule tidak dapat dibuktikan kebenarannya. Lebih lagi, perayaan yang dimaksud dalam kenyataannya tidak memiliki anteseden, sehingga dapat dikatakan bahwa tuturan demikian tidak bersesuaian dengan maksim kualitas. Dengan begitu, pelanggaran tersebut memunculkan implikatur, yakni menyatakan sesuatu yang tidak didukung bukti. Ketidakbenaran informasi dalam tuturan itu tentunya disengaja untuk memancing kegelian penonton. Michael Jackson (dan moonwalk-nya) dan hari pacul sedunia merupakan dua entitas yang secara asosiatif terlampau berjauhan.

Di samping maksim kualitas, pelanggaran terhadap maksim hubungan juga kerap terjadi dalam gelar wicara IT. Kontribusi yang diberikan pelibat tidak relevan dengan apa yang sedang diperbincangkan, seperti tertampak pada data berikut.

(Konteks: Adul [satpam] membawa hadiah untuk Hetty Koes Endang. Sule melarangnya dan menyuruh Adul membawa pergi hadiahnya.)

Sule: "Ya sudah, bawa lagi ke sana!"

Adul: "Nggak ada uang kerohanian apa?"

Sule: “Ah, berarti Lo modus mah. Datang ke sini mau ngasih hadiah tautaunya Lo butuh duit." (IT-02/PKS/28/09)

Di dalam percakapan di atas terlihat bahwa tuturan kedua tidak berpautan dengan tuturan lainnya, meski secara kontekstual tidak mengganggu kelancaran komunikasi. Tuturan bermodus pertanyaan itu dimaksudkan untuk meminta atau memohon sesuatu. Pelanggaran terhadap maksim hubungan ditunjukkan oleh adanya ketidaksesuaian antara permintaan penutur dan topik pembicaraan, yakni uang kerohanian dan pemberian hadiah. Ketidakbergayutan itu menjadi sumber kelucuan bagi penonton, apalagi menyadari peran penutur sebagai satpam. Tuturan tersebut sesungguhnya, selain prinsip kerja sama, juga melanggar prinsip kesantunan, yakni kesantunan negatif. Di balik tuturan terdapat tindakan mengancam muka negatif mitra tutur karena permintaan penutur mengikatnya pada keharusan untuk melakukan sesuatu-memberikan uang.

(Konteks: Andre memerankan sosok Deddy Corbuzier, yang dikenal pernah dekat dengan Vicky Shu [bintang tamu]. Ia membawa hadiah untuk Vicky Shu.)

Sule: "Om Deddy, katanya mau kasih hadiah buat Vicky?" 
Andre: "Memang, ada sesuatu.

Sule: "Hadiah apa yang mau dikasih?"

Andre: "Saya itu sebetulnya sudah lama nyimpan hadiah ini. Mau saya kasih sama Vicky. Cuman karena proses waktu, dan juga waktu yang bergulir, sehingga ion-ion, sehingga kesempatan itu baru ada sekarang."

Sule: "Pak, jangan kebanyakan ngomong, Pak! Ntar keluar kecoa di sini (sambil menunjuk kepala sendiri)." (IT-01/PKS/27/09)

Wacana di atas menunjukkan adanya pelanggaran terhadap maksim cara (manner). Kontribusi yang diberikan Andre berupa memberitahukan, tetapi karena diutarakan secara panjang lebar bahkan tidak jelas, tuturan itu kemudian melahirkan implikatur menyatakan sesuatu secara bertele-tele. Tentu saja, tuturan tersebut menyukarkan mitra tutur memahami pesan. Pilihan bertutur semacam itu justru menyenangkan penonton. Terbukti dengan sambutan tawa yang cukup riuh.

\section{Pelanggaran terhadap Prinsip Kesantunan}

Bagi Brown dan Levinson, suatu tindak tutur dapat menjadi ancaman terhadap muka, yang kemudian mereka sebut sebagai Face Threatening Act (FTA). Ancaman ini menunjukkan bahwa di dalam berkomunikasi kita tidak selalu mematuhi maksim-maksim prinsip kerja sama karena adanya tuntutan untuk berbicara santun. Prinsip kesantunan yang dirumuskan Brown dan Levinson (1987: 70) berkisar pada nosi muka (face), yang terdiri atas muka positif dan muka negatif. Atas dasar itu pula mereka membagi kesantunan menjadi kesantunan positif dan kesantunan negatif.

Kesantunan positif berkenaan dengan muka positif, yakni citra diri orang yang berkeinginan agar apa yang dilakukannya, apa yang dimilikinya, atau nilai-nilai yang diyakininya diakui orang lain sebagai sesuatu yang baik, yang patut dihargai, dan sebagainya. Muka positif yang terancam tampak pada kutipan berikut.

(Konteks: Meriam Bellina [bintang tamu] menyebut Nunung yang mengikuti karakternya sebagai trend setter antagonis.

Kemudian Nunung tertawa.)

Meriam: "Jangan ketawa!"

Westny: "Kalau ketawa polling-nya naik."

Komeng: "Ibu ketawa kayak bawa puding, bergetar semuanya." (IT-02/PK/26/09)

Pelanggaran terhadap kesantunan positif yang dilakukan penutur tampak disengaja untuk menciptakan efek humor. Muka positif mitra tutur terancam oleh tuturan penutur karena mengandung implikatur mengejek. Perumpamaan itu dimaksudkan untuk mengimplisitkan keadaan tubuh mitra tutur yang gemuk. Tindakan demikian merupakan ancaman bagi mitra tutur karena kondisi tubuhnya tidak dihargai oleh penutur. Namun, pelanggaran tersebut sekaligus memberikan efek lucu bagi para penonton, tidak terkecuali mitra tutur sendiri.

Kesantunan negatif berkenaan dengan muka negatif. Muka ini merujuk ke citra diri orang yang berkeinginan agar dihargai dengan cara membiarkannya bebas melakukan sesuatu atau membiarkannya bebas dari keharusan mengerjakan sesuatu. Tuturan yang tidak mengikuti keinginan muka negatif berarti melanggar kesantunan negatif. Akan tetapi, dalam konteks wacana humor pelanggaran itu bukanlah menjadi masalah karena pelibat sama-sama menyadarinya sebagai strategi menciptakan humor.

(Konteks: Nunung menjadi sumber masalah bagi orang lain, hingga memicu perdebatan antara pembawa acara, bintang tamu, dan Yujeng [penegak hukum bagi yang melanggar aturan tidak boleh menyebut orang lain dengan sebutan negatif].)

Komeng: "Bu, jadi masalah nih Ibu di sini nih."

Nunung: "Biarin aja. Emang gue pikirin?" (IT-03/PK/26/09) 
Citra diri mitra tutur (Nunung) pada wacana di atas terancam. Kebebasannya untuk bertindak dan menentukan tetap berada di arena gelar wicara diganggu oleh penutur (Komeng). Tuturan penutur secara tegas memperlihatkan pelanggaran terhadap kesantunan negatif. Hal itu tampak dari implikatur yang ditimbulkan berupa mengusir mitra tutur dari arena itu karena keberadaannya dianggap selalu melahirkan masalah. Sungguhpun begitu, mitra tutur tetap bersikap tenang dan apatis terhadap tindak yang mengancam mukanya itu. Tindak mengusir yang disiratkan penutur justru menjadi penunjang humor bagi penonton yang diekspresikan dengan tawa. Berlainan halnya jika fenomena itu terjadi di dalam suatu interaksi sosial yang wajar.

Dalam pada itu, ditemukan pula bentuk pelanggaran terhadap kedua jenis kesantunan itu secara bersamaan, sebagaimana tertampak pada data berikut.

(Konteks: Bolot [Pak RT] bertepuk tangan saat salah satu bintang tamu masih berbicara. Komeng [consultant host] pun menegur.)

Komeng: "Belum. Belum. Tangannya lihat! (sambil menunjuk tangan para bintang tamu). Belum. Baca koran nggak tadi pagi? Konsultan bunuh RT." (IT01/PK/23/09)

Brown dan Levinson (1987: 67) telah menengarai ihwal adanya tumpang tindih dalam klasifikasi FTA karena sejumlah tindakan secara intrinsik mengancam muka positif dan muka negatif sekaligus (misalnya pengaduan, interupsi, ancaman, ungkapan emosional yang kuat, permintaan informasi pribadi). Fungsi pragmatis mengancam pada tuturan di atas tidak diekspresikan secara eksplisit, sehingga berupa implikatur. Penutur menyiratkan ancaman dengan modus memberitahukan. Siratan tersebut dikatakan mengancam muka positif karena apa yang dilakukan mitra tutur (Bolot) tidak dihargai oleh penutur; sedangkan, muka negatif mitra tutur terancam karena keinginannya untuk melakukan sesuatu, yakni bertepuk tangan, tidak dibebaskan oleh penutur. Meski begitu, ancaman yang berlebihan itu justru mampu memancing tawa penonton. Ini berarti bahwa pelanggaran terhadap prinsip kesantunan disengaja agar melahirkan implikatur yang berkekuatan humor.

\section{SIMPULAN}

Untuk menciptakan suasana humor, pelibat yang berinteraksi dalam wacana gelar wicara IT kerap kali menggunakan strategi bertutur tidak langsung, yakni dengan memanfaatkan implikatur. Terdapat sejumlah wujud implikatur yang diutarakan, seperti menyebutkan, menyatakan, menolak, menyindir, memprotes, menuduh, mengklaim, memintalmemohon, mengejek, mengusir, dan mengancam. Pelahiran implikatur tersebut akibat tidak mengindahkan prinsip percakapan, baik prinsip kerja sama maupun prinsip kesantunan. Meski demikian, lalu lintas percakapan tetap berjalan lancar dan tidak menimbulkan ancaman terhadap relasi sosial di antara pelibat. Hal demikian disebabkan adanya kesamaan pemahaman ihwal kontribusi yang mereka berikan pada interaksi itu semata-mata untuk menimbukan efek lucu di benak penonton.

\section{PERSANTUNAN}

Peneliti mengucapkan terima kasih kepada berbagai pihak yang telah membantu dalam proses penelitian ini.

\section{DAFTAR PUSTAKA}

Bell, Nancy D. dan Anne Pomerantz. 2016. Humor in The Classroom: A Guide for Language Teachers and Educational Researchers. New York: Routledge.

Birner, Betty J. 2013. Introduction to Pragmatics. Chichester, West Sussex: Wiley-Blackwell.

Brown, Gillian dan George Yule. 1983. Discourse Analysis. Cambridge: Cambridge University Press. 
Brown, Penelope dan Stephen C. Levinson. 1987. Politeness: Some Universals in Language Usage. Cambridge: Cambridge University Press.

Grice, H.P. 1975. "Logic and Conversation." Dimuat ulang dalam Adam Jaworski dan Nikolas Coupland (Ed.). 2006. The Discourse Reader. New York: Routledge.

Holmes, Janet. 2013. An Introduction to Sociolinguistics. London: Routledge.

Horn, Laurence R. 2006. "Implicature." Dalam Laurence R. Horn dan Gregory Ward (Ed.). The Handbook of Pragmatics. Malden, MA: Blackwell Publishing Ltd.

Leech, Geoffrey. 1983. Principles of Pragmatics. London: Longman.

Martin, Rod A. 2007. The Psychology of Humor: An Integrative Approach. Burlington, MA: Elsevier Academic Press.

Mey, Jacob L. 2004. Pragmatics: An Introduction. Malden, MA: Blackwell.

Miles, Mattew B. dan A. Michael Huberman. 1994. Qualitative Data Analysis: An Expanded Sourcebook. Thousand Oaks, California: Sage Publications.

Raskin, Victor. 1985. Semantic Mechanisms of Humor. Dordrecht: D. Reidel Publishing Company.

Searle, John R. 1969. Speech Acts: An Essay in the Philosophy of Language. London: Cambridge University Press.

Yule, George. 2014. The Study of Language. Cambridge: Cambridge University Press. 